\title{
ADAPTED CONFLICT RESOLUTION MODEL IN BUSINESS ORGANIZATIONS
}

\author{
Iv. Ivanov* \\ Industrial Business Department, Faculty of Business, University of National and World Economy - \\ Sofia, Bulgaria
}

\begin{abstract}
The success of any modern business organization increasingly depends on its ability to manage and resolve conflicts. The development and implementation of an adequate conflict management technology in business becomes a priority task for Bulgarian business organizations. Conflict resolution, as part of the overall process of Business organization management, is a key driver for efficiency gains. The present paper provides an adapted model for conflict resolution in business organizations as a whole. The aim of the paper is to provoke a scientific discussion of the problem presented here. Such kind of development would provoke a scientific search for other, more efficient ways of putting existing conflict theory and methodology into practice. The development of this specific management activity is on the agenda for both scientists and practitioners. The cooperation between them is crucial for the development and implementation of adequate best practices in this area of study.
\end{abstract}

Key words: Conflict forecasting, Conflict prevention, Conflict stimulation, Conflict regulation, Management

\section{INTRODUCTION}

Conflicts, whether we like it or not, are an integral part of the life cycle of people and socio-economic systems, which they create to achieve their goals. Throughout history, conflict, as a universal human phenomenon has constantly excited interest in scientists from all fields of science. With the development of management there is a growing practical interest in conflict management in organizations. The interest in that problematic area, especially in business organizations, is aroused by the need to look for solutions of a number of questions related to increasing the effectiveness of management and the overall activity of the business. At present, modern theory and practice of conflicts and their management cannot and do not undoubtedly claim to provide a heal-all to the array of problems which modern environment and internal conditions in organizations present to business. It is the aim of the present paper to

Ivaylo Ivanov, 1700 Sofia, Bulgaria, Studentski grad "Hristo Botev", University of National and World Economy, Office 4035, Tel.: (+359 2) 81952-67, E-mail: i.ivaylo@unwe.bg provoke a scientific discussion on a number of issues, which are of interest for the author in his scientific research. One of them is related to the development of an overall methodology for evaluation, analysis and solution of conflicts in Bulgarian business organizations. It is not about a methodology claiming to be universal, but rather one that to a great extent will take into consideration the specificity of the business environment in Bulgaria and offer appropriate solutions. As a step in that direction the immediate task the author has set himself is to seek the opinion of the representatives of science and of the practitioners on an existing, present in theory verbal model of conflict resolution in business organizations. It is this adapted model that the author intends to use to attain his final goal. Bulgarian society is permeated by conflicts of various nature. The prevailing feeling is that most of them will further intensify. Only time will tell whether the situation will go in that direction. For us - that part of the scientific community which studies the problems of managing business, and the representatives of business, there is the unsolved task to jointly 
develop, offer and apply adequate management technologies and best practices in the field of management and conflict resolution. There are a number of problems Bulgarian business is going to face. For the time being let us focus on three of them - mass demotivation (1) and demoralization in Bulgarian society, combined with its demographic shrinkage. It is obvious from their development that the creation and implementation of working technologies in the abovementioned field may turn out to be of top priority. As a supporter of the strategy "survival through development" the author believes that the success of a business organizations in Bulgaria depends on their ability to manage and resolve their conflicts. It is our belief that it will happen but only after we make the first step of tuning in our way of thinking towards discovering opportunities in the problems around us and swing into action.

\section{CONFLICTS AND THE STATE OF CONFLICT MANAGEMENT SCIENCE IN BULGARIA}

After the radical change of 1989 Bulgarian society has been afflicted by unfamiliar conflicts, which have brought the science of social conflicts and their management conflictology, to the forefront and it has attracted considerable scientific and public interest. The scientific community and public practice have had and still have a burning need for new, theoretical knowledge of conflicts, which will enable us to solve topical issues and practical tasks. Due to the efforts of a small circle of Bulgarian scientists and researchers we are witnessing the further development of a new sphere of scientific knowledge for our country- conflictology (2).

Conflicts, which resulted from the transformation of Bulgarian society and economics, had a direct impact on the effectiveness and the quality of Bulgarian business organizations. Modern studies and research (3-7) report the wide awareness and recognition of the growing significance of conflicts in all spheres of life on a regional, national and world scale.

The generic definition of conflict we have used has been formulated by the founder of modern science of social conflict in Bulgaria Prof.DSc. Dimitar Yordanov Dimitrov. It is generally accepted that Conflict is a form of manifestation of contradictions - a universal and eternal human and public phenomenon, based on the dynamic interaction between at least two conflicting parties, caused by different interests, needs, goals, values, opinions and lack of resources where means of various nature are used to achieve the goals and satisfy the interests; it ends in victory, defeat, compromise or a mutually acceptable solution (8).

\section{THE AIM AND THE FOCUS OF THE PAPER}

The focus of the present paper is on conflict as a phenomenon related to individuals and business organizations, which people establish or participate in. Conflict is of interest in terms of the objective laws for its occurrence (prerequisites for its occurrence, development, ending, effects and situations after its end) in their entirety. Conflictological relations between individuals and social groups -namely business organizations and their activities, are studied. The aim is to get to know various means and ways of impacting (analysis, forecasting, prevention, practice) conflicting relations of the interacting parties. That activity is not an end in itself. It is a step forward in technologizing the acquired knowledge in the field of conflict management. In the end this is one of the ways for solving practical problems related to conflicting interaction in business organizations.

The development of such an understanding of the nature of the processes under study is based on the achievement of many researchers with acknowledged contribution in the science and practice of conflictology such as Boulding (9), Burton (10, 14), Darendorf (11), Kriegsberg (12), Boardman and Horowitz (13), Deutsch (15) and many others.

As a result of their theoretical and practical work the thesis was adopted that conflict management is of heuristic importance for creating a technology for taking complex decisions about the management of a business. The present work is the starting point for proving it. There is the assertion that the mechanisms of conflict resolution play a significant role in the technology of conflict management in a business organization.

However, there are the questions of what the specificity of conflicts in a business organization is, what the main directions of the analysis of existing and potential conflicts are.

\section{METHODOLOGICAL FRAMEWORK}

The assertion that each organization is characterized by its own internal and external 
environment has long been widely accepted. The internal environment of an organization is characterized by its functional structure, aims and tasks, resources, technologies and communications. The external environment of an organization in turn is determined by different in nature factors and social conditions of the environment. It is their adequate diagnostics that is at the base of the strategic analysis and the successful implementation of the views on the strategy of the business organization. If we set the strategic aspect of management aside then our attention turns to the tactical and operational level of management. And there are lurking conflicts in the organization. That is a factor which in Bulgarian research in the field of management has received only cursory treatment and has almost been ignored in public and business practice.

To a great extent contradictions along the axes of "Individual - Group", Intragroup and Intergroup conflicts are at the basis of conflicts in the organization. These kinds of conflicts play a prominent role in the process of social interaction and realization of human activities. And it is not only within the framework of a particular organization but also in the interaction between different organizations. Inadequate interaction along these axes, in their formal and informal dimension, together with interpersonal relations is often a major factor causing conflicts in organizations.

Such a short overview of the types of conflicts in an organization, based on the participants in the conflict, is the minimal required, but insufficient basis for dealing with conflicts. We should not fail to mention the sources of conflicts in organizations, which can be summarized in four types - structural conflicts, innovation conflicts, position conflicts and resource conflicts. We could add yet another characteristic for classifying conflicts in organizations -the type of functional system of the organization. It determines them as organizational-technological conflicts, conflicts in the socio-economic system of the organization and conflicts in the administrative-management system of the organization. That typology comes to aid the overall technologization of the management of conflicts. Their effective solution, as the final goal of the study, is only an element (and a final one) of the whole process of managing them.

\section{THE LOGIC OF CONFLICT MANAGEMENT AND THE ROLE OF CONFLICT RESOLUTION}

What is the logic that is applied. Managing conflict is a purposeful management impact. That impact is exerted on the behaviour and the actions of individuals and groups in their conflict and regarding their conflict interaction. The final aim is solving the conflict as a whole or at different stages of its dynamics of unfolding.

The very process of managing the conflict is quite complicated but for the purpose of the goals set herein it can be brought down to three main stages. They are: "Appeasing the conflict", "Resolving the conflict" and "Reaching a mutually beneficial compromise solution among the parties".

It is the area of Resolution of conflicts that is the focus of our scientific and practical work. At the risk of repeating myself - the main aim is the following: - by means of the already acquired conflictological knowledge to technologize the process of resolving the conflict, as the final stage in managing it. At the same time opportunities will be sought to mitigate the causes of conflicts and to overcome or minimize the consequences of the so called destructive and dysfunctional conflicts.

Which are, however, the other steps that are part of the process of managing conflicts and precede its final resolution. All steps presented below are taken by those making the managerial decisions at different levels of the organizations.

First comes forecasting of conflicts. That is the activity of the one who makes managerial decisions and it is directed at clarifying the reasons for the potential development of a certain conflict or conflicts. What comes next is prevention of conflicts - an activity directly targeted at averting a conflict or conflicts. Sometimes there is the need for stimulating a conflict - an activity targeted at provoking (causing) a conflict. Quite often it is necessary to regulate a conflict - an activity targeted at abating and limiting conflicts. In the end comes resolution of conflicts, which includes all the activities of the manager related to ending the conflict. The maximum to be achieved is complete resolution of the conflict through elimination of its causes and the conflict situation. The result aimed at is reaching mutually beneficial, lasting and final 
agreement regarding the real subject of the disagreement between the parties in the conflict. Quite often, however, its resolution is incomplete - not all causes and accompanying conflict situation are eliminated. However, that is a matter for further consideration.

There must be a range of prerequisites for resolving a particular conflict. The conflict should be mature enough. There should be the need in the parties in the conflict to have it resolved. What should not be overlooked also is the availability of the needed means and resources for resolution of the conflict.

Before moving on to the essence of the proposed adapted, staged model of resolution of conflicts we need to say a few words about the prerequisites and forms of conflict resolution in business organizations. In general, the forms of conflict resolution will depend on the chosen strategies of behaviour in these particular situations. According to research carried out by Kilmann, R. H. and Thomas (16), (17) the classical strategies for settling the conflict are competition, compromise, adaptation, avoidance and cooperation. It is important to mention them because often the adequate or inadequate adoption of one of these determines the final result of a conflict. A more detailed discussion of them, however, is outside the scope of the present study. As far as the ways of resolving a conflict are concerned we would summarize them, without going into details, into two main ways - administrative and pedagogical.

\section{THE DESCRIPTIVE MODEL OF CONFLICT RESOLUTION IN BUSINESS ORGANIZATIONS}

The main understanding, the accepted logic of the described processes as well as the proposed adapted model are based mostly to the philosophy of Prof. Dimitrov presented in the abovementioned fundamental work "Conflictology"of 2004. They are complemented by the revised works of Professor Luchian Milkov of 2014 (18) and other Bulgarian authors such as Atanas Gotchev (19) and Evgenia Vasileva (20). Full credit should be given to the impact of worldrenowned or new sources in the field of conflict resolution which have been cited in this paper.

Here follows a description of the proposed model. In essence it is a staged, descriptive model of conflict resolution in general. The use of the word adapted in its description is due to the fact that it, when applied, takes into consideration the specificity of the business organization, for example, in organizing and conducting business negotiations, the specific actions for resolving the conflict, cultural characteristics, the limitations of the industry characteristics, the sphere of activity, the application of the situational approach and many other.

In essence the model for conflict resolution of the business organization is based on the execution of the following five stages with their particular aims:

Stage one - Prevention of conflict. That stage as a whole pursues the following two objectives. The first of them is the earliest possible diagnostics of a prospective conflict interaction. The second one is related to performing the needed actions in order to prevent a destructive conflict.

Stage two. It is related to the Analysis of the conflict situation. In the second stage we need to take the following actions. First to forecast the conflict in its general lines of development, the way it goes and ends and its social background. The subject and the object of the conflict need to be distinguished. We cannot do without an analysis of the parties participating in the conflict. What is needed also is an analysis of the managerial position of the individual entrusted with the task of organizing the process of resolution of the conflict.

Stage three. It is related to the Preparation of a strategy for resolution of the conflict.

That third stage includes several objectives. Choosing particular strategies for conflict resolution is the first of them. Next follows the preparation of a particular programme (action plan) for following the strategy for conflict resolution. The preparation of criteria which will be used to evaluate the effective resolution of the conflict is the last objective at this stage.

\section{Stage four - Implementation of the strategy for conflict resolution.}

At that stage the precise and consistent implementation of the strategy for conflict resolution is monitored, and when necessary, the needed measures and actions are taken to control and correct the strategy, on the basis of the information (feedback) about the object (objects) of managerial impact. The respective ending of the conflict happens at that stage. 
Stage five. Analysis of post-conflict situation. In that final fifth stage the most important thing to do is to perform three main actions. The first is the evaluation of the effectiveness of the actions taken for conflict resolution. The next step involves an overview of the experience acquired, with its positive and negative sides. Finally, action should be taken regarding the prevention of other conflicts and most of all destructive ones.

In general, this is what the model for conflict resolution in business organization, proposed here for discussion, is about. Looking back at the correlation "conflict managementconflict resolution" another applied tool can be added to the here presented model. It enriches the possibilities of analyzing and managing conflicts in a business organization. That is the algorithm of managing conflict by leaders developed by Prof. Dimitrov. It is based on a strict sequence of steps, whose execution leads to a potentially successful management of the conflict. Its logic does not contradict but rather complements the available practical tools for handling conflicts.

\section{ALGORITHM FOR MANAGING CONFLICTS BY LEADERS.}

The first step is the study of the causes of the conflict. The causes of a conflict in general are:

1) Objective (do not depend on the cognizance of those participating in the conflict);

2) Subjective (subjectively true reflect the objective reality by the participants in the conflict);

3) Subjectivist (are the fruit of the active imagination of the participants in the conflict).

Techniques (methods) of execution:

a) Observation (of the conflict and of the participants in the conflict). In this case the manager is in a passive position;

b) Analysis of the results from the activity (of the participants in the conflict);

c) Talk (with the participants in the conflict). Here the manager is in an active position and has a purposeful conversation with the participants in the conflict interaction;

d) Study (analysis) of documents (directly or indirectly related to conflict and the participants in the conflict);

e) Biographical method (of the conflict and the participants in the conflict).

Step two - limiting the number of participants.
Limiting the number of the participants in the conflict is a very important moment in managing it. What is more, we should not allow the subject of conflict interaction to expand.

Techniques (methods) of execution:

a) Work with the leaders in the microgroups. Identification of the leaders in the microgroups and influencing them with the aim to limit the number of the participants in the conflict interaction;

b) Redistribution of functional responsibilities. In some cases there may be the need to move the conflict participants in the organization and change the nature of the activity they are involved in;

c) Awards and sanctions, etc. The whole range of techniques for stimulation (external influence on the participants in the conflict) and motivation (internally recognized needs combined with external influence on the participants in the conflict).

Step three - additional analysis of the conflict by experts.

That step is highly needed in a continuous conflict or in a conflict involving a great number of participants.

\section{Techniques (methods) of execution:}

a) Survey of experts. In this case it is best that they are experts in the field of the conflict which has occurred (economic experts in an economic conflict, experts in the field of management in managerial conflicts, etc.);

b) Attracting a conflictologist, a mediator, a psychologist. Each of the three types of experts has its specific role and place in managing the conflict. The conflictologist is most appropriate as expert in organizational conflicts, the psychologist is best used as expert in intrapersonal or interpersonal conflicts, the greatest strength of the mediator (intermediary) is demonstrated in conflictological mediation and negotiations;

c) Negotiating process (mediation), etc. By and large the negotiating process and its specific conflictological variation - mediation are only a tool for managing conflict. The decisions and activities about its real management are made and carried out by the manager and the participants in the conflict, with the mediator just providing assistance in the process.

\section{Step four - decision making.}

In the end, it all comes down to making decisions about managing the conflict. 
Techniques (methods) of execution:

a) Administrative methods. They are used if the leader has administrative power (regulated) - stimulation and sanctions;

b) Pedagogical methods. These include a rich array of psychological, socio-psychological and social methods of influence. For example, persuasion, request, clarification, pressure, advice, etc.

As a whole that is the theoretical statement of the model, which has been tested in a real business environment. There is a lot of work to be done on improving it and testing it on a statistically relevant scale. Ways are sought to integrate into the herein described model other appropriate instruments for managing and resolving conflicts in business organizations. In today's highly dynamic environment this is not a hindrance. It is even obligatory, as a supplement to the model here proposed and the accompanying algorithm, to employ what other models can offer. A good example in this respect is the "CHANGES: A Conflict Management Model for Organizational Redesign Efforts "model (21).

The beginning of the road has been marked and as Laozi says 'A journey of a thousand Chinese miles (li) starts beneath one's feet'.

\section{CONCLUSION}

As the attentive reader has already noted there is a difference between the definitions and the essence of the concepts of conflict management and conflict resolution, although they are of similar nature. Generally, it is much easier to manage a certain conflict than to resolve it. There are even authors who claim that a conflict can be managed only but not solved because the resolution of the conflict interaction is related to phenomena which cannot be influenced: the needs, motives and interests of the individual, value orientation and social attitudes, etc. The author of this paper does not agree with such an extreme view. Public and business practices provide many examples which prove the theoretical possibility of conflict resolution. That possibility, of course, can be realized under certain subjective and objective prerequisites and conditions (8).

The adapted model for conflict resolution proposed here is at present being tested in Bulgarian business organizations from various sectors. The plan is, over a period of two years, to achieve results which will empirically prove the degree of its effectiveness. The answer to the question whether this choice of a theoretical structure of the here proposed descriptive model of conflict resolution was reasonable can and will be obtained only through public practice. At the moment all advice about its optimization, all ascertainments, conclusions and recommendations about its adequacy are welcome. The author relies on the scientific community and experts from practice to get involved in the discussion he has initiated. A well-meant and open discussion is the way to find simple solutions to the complex problems that we create ourselves or the environment, in which we pursue our activities and goals, presents us with. It is the aim of the author to make a contribution in the field of conflict resolution in business organizations. It is his belief that collaborative work can make this aim attainable.

\section{REFERENCES}

1. Angelova, M. Research and overcoming the demotivation of human resources. Dissertation, UNWE, Sofia, 2014.

2. Dimitrov, D. Y., Conflictology and conflictological culture, Economic Alternatives (In Bulgarian), 4: 2004.

3. Furlong GT. The Conflict Resolution Toolbox : Models and Maps for Analyzing, Diagnosing, and Resolving Conflict. Mississauga, Ont: Wiley; 2005.

4. Team Publications. Conflict Resolution. Vol 2nd edition. ReadyToManage; 2006.

5. Booher DD. The Conflict Resolution Bible: A Quick Reference Guide for Resolving Conflict in the Workplace. Colleyville, Tex: Booher Research Institute; 2013.

6. Mukherjee J. Conflict Resolution in Multicultural Societies: The Indian Experience. New Delhi, India: Sage Publications Pvt. Ltd; 2014.

7. Hansen, T. The Generalist Approach to Conflict Resolution: A Guidebook. Lanham: Lexington Books, 2013.

8. Dimitrov, D. Y. Conflictology, Publishing complex "Stopanstvo". (In Bulgarian). Sofia, Bulgaria, 2004.

9. Boulding, K. E., Conflict and Defense: A General Theory, New York, Harper, 1962.

10.Burton, J. W., Conflict: resolution and prevention, N.Y.: St. Martin's Press, 1990. $-24,295 \mathrm{p}$.

11.Darendorf, R., The modern social conflict. An essay on the politics of liberty, Berkeley: University of California Press, 1990. 
12.Kriegsberg, L., Social Conflicts. Englewood-Clifts, N.J.: Prentice-Hall, 1982 $-13,394 \mathrm{p}$.

13.Boardman S., Horowitz S. Constructive Conflict Management and Social Problems: An Introduction // Journal of Social Issues. - 1994. - Vol. 50. - No. 1 - pp. 1 - 12.

14.Burton, The Theory of Conflict Resolution // Current Research on Peace and Violence. - 1986. - Vol. 9. - No. 3. - pp. 125 - 130.

15.Deutsch, M. Constructive Conflict Resolution: Principles, Training and Research // Journal of Social Issues. 1988. Vol. 50. - No. 1. - pp. 13-32.

16. Thomas, K. W., Conflict and negotiation, Handbook of Industrial and Organizational Psychology, Eds. M. D. Dunnette, Palo Alto, CA, 1992.
17.Kilmann, R. H., and Thomas, K. W.,. Developing a Forced-Choice Measure of Conflict-Handling Behavior: The MODE Instrument. Educational and Psychological Measurement, 37(2), pp. 309-325., 1977.

18. Milkov, L. Conflictology, Uni Express, (In Bulgarian), Sofia, 2014.

19.Gotchev, A. The Conflict - Theories and approaches for its resolution. Albatros, (In Bulgarian), Sofia, 2011.

20. Vasileva, E. The Conflict - Models and Case studies. Albatros, (In Bulgarian), Sofia, 2012.

21.Patton, C. CHANGES: A Conflict Management Model for Organizational Redesign Efforts. Journal of Conflict Management. Volume 6, Number 1:26-40, 2018. 